ARTICLE

Received 6 Jan 2017 | Accepted 20 Apr 2017 | Published 12 Jun $2017 \quad$ DOl: 10.1038/ncomms15719 OPEN

\title{
Cryogenic strength improvement by utilizing room-temperature deformation twinning in a partially recrystallized $\mathrm{VCrMnFeCoNi}$ high-entropy alloy
}

\author{
Y.H. Jo1, S. Jung ${ }^{1}$, W.M. Choi ${ }^{1}$, S.S. Sohn', H.S. Kim¹, B.J. Lee ${ }^{1}$, N.J. Kim² \& S. Lee
}

The excellent cryogenic tensile properties of the $\mathrm{CrMnFeCoNi}$ alloy are generally caused by deformation twinning, which is difficult to achieve at room temperature because of insufficient stress for twinning. Here, we induced twinning at room temperature to improve the cryogenic tensile properties of the $\mathrm{CrMnFeCoNi}$ alloy. Considering grain size effects on the critical stress for twinning, twins were readily formed in the coarse microstructure by cold rolling without grain refinement by hot rolling. These twins were retained by partial recrystallization and played an important role in improving strength, allowing yield strengths approaching $1 \mathrm{GPa}$. The persistent elongation up to $46 \%$ as well as the tensile strength of 1.3 GPa are attributed to additional twinning in both recrystallized and non-recrystallization regions. Our results demonstrate that non-recrystallized grains, which are generally avoided in conventional alloys because of their deleterious effect on ductility, can be useful in achieving high-strength high-entropy alloys.

\footnotetext{
${ }^{1}$ Center for High Entropy Alloys, Pohang University of Science and Technology, Pohang 790-784, Korea. ${ }^{2}$ Graduate Institute of Ferrous Technology, Pohang University of Science and Technology, Pohang 790-784, Korea. Correspondence and requests for materials should be addressed to S.S.S.

(email: bbosil7@postech.ac.kr).
} 
$\mathrm{N}$ ew unique alloys with five or more elements present in similar portions within the alloy that have preferentially solid-solution phases have been developed as a class of high-entropy alloys (HEAs) ${ }^{1-4}$. These HEAs exist as single multielement solid solutions, have excellent thermal stabilities ${ }^{5-7}$, are generally composed of a single phase of face centered cubic (fcc) or body centered cubic (bcc), and have properties that vary depending on the types and amounts of alloying elements ${ }^{8-11}$. Among these HEAs, an equi-atomic CrMnFeCoNi five-component alloy developed by Cantor et al. ${ }^{12}$ features strongly temperaturedependent strength and ductility, and its cryogenic-temperature strength and ductility are much higher than those at room-temperature because of its fcc structure and deformation twinning ${ }^{13-17}$. HEAs show better fracture toughness and corrosion resistance at cryogenic temperatures than conventional stainless steels used for cryogenic applications ${ }^{15-19}$. Because the properties of HEAs, including the $\mathrm{CrMnFeCoNi}$ alloy, correspond well with those of structural materials for cryogenic extreme-environmental applications, the successful replacement of $9 \%-\mathrm{Ni}$ and stainless steels with HEAs can be expected.

The excellent tensile properties of the CrMnFeCoNi alloy at cryogenic temperatures are mainly caused by deformation twinning $14,15,20$. However, such twinning is difficult to achieve at room temperature because the resolved shear stress is insufficient to reach the critical stress for twinning ${ }^{20,21}$. Another issue is the relatively low yield strength $(0.2-0.6 \mathrm{GPa})$ caused by the fcc structural characteristics of the alloy $14,20,22-24$. Here, we effectively induce twinning in an HEA at room temperature and exploit the induced twinning to improve the cryogenic tensile properties, particularly the yield strength, of the material. Because the critical twinning stress depends on the grain size, which provides a significant potential for twinning at room temperature ${ }^{25-27}$, the investigated HEA was cold rolled right after a homogenization treatment without a hot-rolling process and was annealed at 750 and $900{ }^{\circ} \mathrm{C}$ for $10 \mathrm{~min}$ to obtain partially and fully recrystallized microstructures, respectively. Due to the utilization of non-recrystallized grains containing retained deformation twins, the HEA showed ultra-high yield and tensile strengths of 0.97 and $1.3 \mathrm{GPa}$, respectively, together with a good ductility of $46 \%$, which surpassed the tensile properties of the existing HEAs. Our results demonstrate that the existence of non-recrystallized regions, which are generally avoided in conventional alloys because of their deleterious effect on ductility, can provide a useful design concept in high-strength HEAs.

\section{Results}

Computational thermodynamic approach for alloy design. The first objective of this research was to develop new VCrMnFeCoNi alloys for use in cryogenic applications. To achieve the chemical compositions of these alloys, a computational thermodynamic approach of a VCrMnFeCoNi six-component system was used, from which HEA compositions having a wide temperature range of an fcc single phase were obtained. This thermodynamicapproach-based alloy design was very effective in comparison with conventional alloying methods, that is, empirical and trial-and-error-based alloy design and property evaluation, which demand significant time and are expensive ${ }^{28,29}$

Vanadium was selected as a new candidate alloying element in the CrMnFeCoNi alloy system because it shows a wide single-phase solid-solution range on binary phase diagrams with most elements, including $\mathrm{Cr}$, Fe and Mn. Although most HEAs have equi-atomic or near-equi-atomic compositions, the equi-atomic composition is not believed to be the optimum composition for a wide range of materials properties. The CrMnFeCoNi alloy system is not a unique system that yields fcc-single-phase microstructures containing more than five components $^{30-35}$. The atomic sizes of all elements in the CrMnFeCoNi alloy are similar to each other, while the atomic size of vanadium is somewhat larger than the other elements. In addition, vanadium could have a larger negative mixing enthalpy and thus possess stronger bonds with $\mathrm{Fe}, \mathrm{Co}$ and $\mathrm{Ni}$ than those among $\mathrm{Cr}, \mathrm{Mn}, \mathrm{Fe}, \mathrm{Co}$ and $\mathrm{Ni}$ (ref. 36). The addition of vanadium could induce a larger solid-solution hardening effect.

The design of a new VCrMnFeCoNi alloy and the theoretical confirmation of an fcc-single-phase equilibrium were carried out with Thermo-Calc ${ }^{37}$ software along with TCFE2000 and its upgraded version ${ }^{38,39}$. Figure 1a shows the equilibrium phase diagram obtained when mole fractions of $\mathrm{Fe}, \mathrm{Mn}$ and $\mathrm{Ni}$ are varied in an alloy containing $10 \mathrm{Co} 15 \mathrm{Cr} 10 \mathrm{~V}$ (at.\%) in the temperature range of $600-800^{\circ} \mathrm{C}$. The compositions located

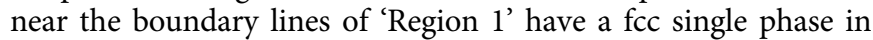
the temperature range of $600{ }^{\circ} \mathrm{C}$-melting point, while the compositions located in the right side of 'Region 1' have two phases $(\mathrm{fcc}+\mathrm{bcc})$. Based on this three-component phase diagram, the $35 \mathrm{Fe} 5 \mathrm{Mn} 25 \mathrm{Ni}$ (at.\%) composition was selected to obtain a stable fcc single phase in the temperature range of $590^{\circ} \mathrm{C}$-melting point. Figure $1 \mathrm{~b}$ shows the calculated mole fractions of the equilibrium phases in the temperature range of $300-1,400^{\circ} \mathrm{C}$. The present $10 \mathrm{~V} 15 \mathrm{Cr} 5 \mathrm{Mn} 35 \mathrm{Fe} 10 \mathrm{Co} 25 \mathrm{Ni}$ alloy has a very wide fcc-single-phase region (gray-colored area) in the temperature range of $590-1,300^{\circ} \mathrm{C}$.

Microstructures. X-ray diffraction patterns of the $750{ }^{\circ} \mathrm{C}$ - and $900^{\circ} \mathrm{C}$-annealed alloys (H750 and $\mathrm{H} 900$ alloys) as well as the as-homogenized alloy are shown in Fig. 1c. Peaks of an fcc single phase are only observed without any peaks of $\mathrm{Co}-\mathrm{Fe}$ bcc or Cr-rich bcc phases, which indicates that the experimental fcc-single-phase microstructures are well matched with those estimated from thermodynamic calculations (Fig. 1a,b).

Figure $2 \mathrm{a}-\mathrm{c}$ shows the electron backscatter diffraction (EBSD) inverse pole figure (IPF) maps of the as-homogenized, H900 and $\mathrm{H} 750$ alloys. The as-homogenized alloy consists of very coarse fcc-single-phase grains of $\sim 157 \mu \mathrm{m}$ in size (Fig. 2a). Equiaxed, recrystallized fcc-single-phase grains of $\sim 5.2 \mu \mathrm{m}$ in size (twin boundaries were not counted in the measurements) are homogeneously distributed in the H900 alloy (Fig. 2b). In the $\mathrm{H} 750$ alloy, fine recrystallized fcc grains (average grain size: $\sim 1.5 \mu \mathrm{m}$ ) are mixed with coarse non-recrystallized fcc grains (average grain size: $\sim 32 \mu \mathrm{m}$; Fig. $2 \mathrm{c}$ ). Most of the fine recrystallized grains are linearly connected along the $35-65^{\circ}$ direction deviating from the rolling direction because the recrystallization occurs preferentially along the $35-65^{\circ}$ shear bands formed during cold rolling. The volume fraction of the recrystallized region is $\sim 40 \%$. Figure $2 \mathrm{~d}$,e shows highermagnification EBSD IPF and image quality (IQ), with kernel average misorientation (KAM) maps of the partially recrystallized microstructure in the $\mathrm{H} 750$ alloy. Fine recrystallized grains are mostly aligned along the $35-65^{\circ}$ direction, and several deformation twins having $60^{\circ}$-twin orientations within the matrix are observed in the non-recrystallized grains (Fig. 2d). These twins are formed during cold rolling and are aligned nearly along the rolling direction, which does not match the orientations of the recrystallized grains. This result suggests that deformation twins can be formed at room temperature, which is discussed in the present study. According to the IQ-KAM map (Fig. 2e), two types of grains are clearly distinguished. The KAM values of the recrystallized grains are lower than $1^{\circ}$, whereas those of the non-recrystallized grains are much higher $\left(1-5^{\circ}\right)$. The non-recrystallized grains are recovered, and the KAM values are somewhat higher near twinned areas than in matrix areas. 

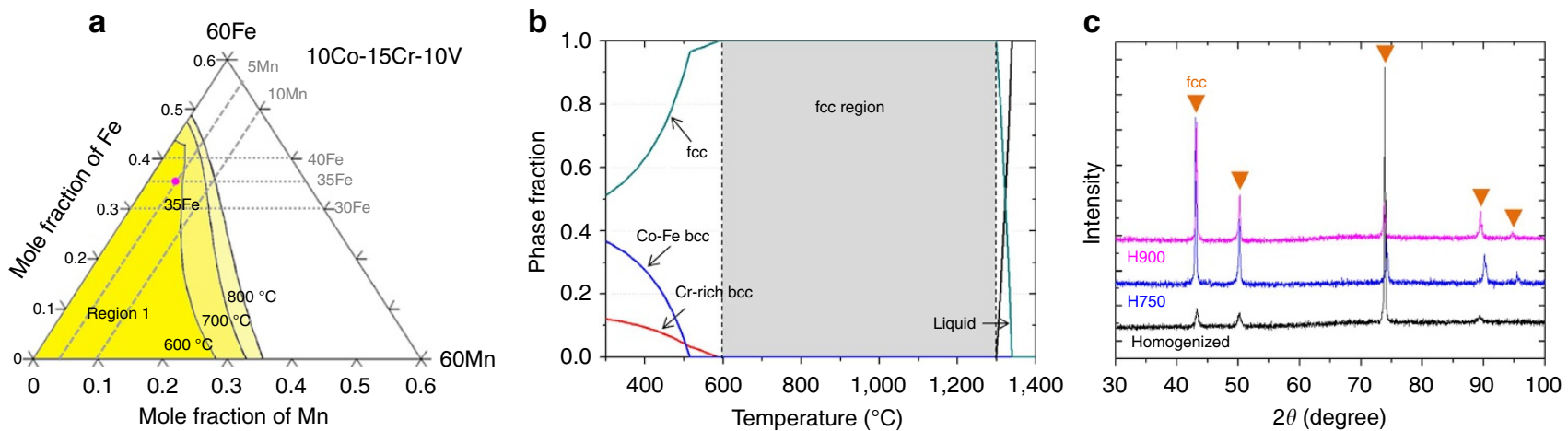

Figure 1 | Equilibrium phase diagrams and experimental microstructure of the designed alloy. (a) Equilibrium phase diagram obtained for varied mole fractions of $\mathrm{Fe}, \mathrm{Mn}$ and $\mathrm{Ni}$ in an alloy containing $10 \mathrm{Co} 15 \mathrm{Cr} 10 \mathrm{~V}$ in the temperature range of $600-800^{\circ} \mathrm{C}$. (b) Mole fractions of equilibrium phases of liquid, $\mathrm{fcc}$, Co-Fe bcc and $\mathrm{Cr}$-rich bcc in the temperature range of $300-1,400^{\circ} \mathrm{C}$. The $10 \mathrm{~V} 15 \mathrm{Cr} 5 \mathrm{Mn} 35 \mathrm{Fe} 10 \mathrm{Co} 25 \mathrm{Ni}$ alloy has a very wide fcc-single-phase region (gray-colored area) in the temperature range of $590-1,300^{\circ} \mathrm{C}$. (c) X-ray diffraction patterns of the $750{ }^{\circ} \mathrm{C}$ - and $900{ }^{\circ} \mathrm{C}$-annealed alloys $(\mathrm{H} 750$ and $\mathrm{H} 900$ alloys). Peaks of an fcc single-phase are only observed without any peaks of $\mathrm{Co}-\mathrm{Fe}$ bcc or $\mathrm{Cr}$-rich bcc phases.

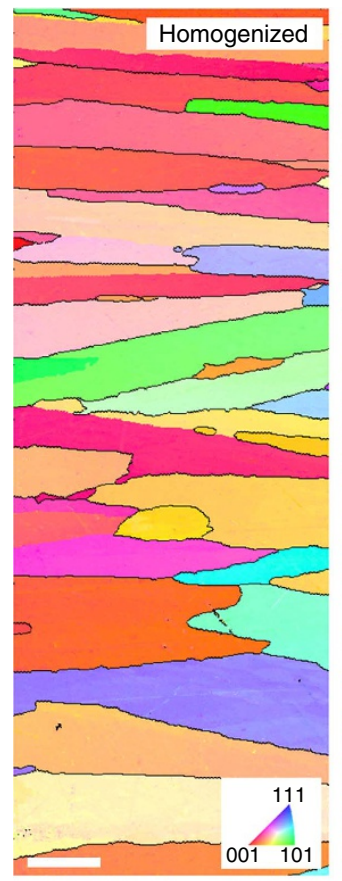

$D: 156.5 \pm 61.3 \mu \mathrm{m}$ b

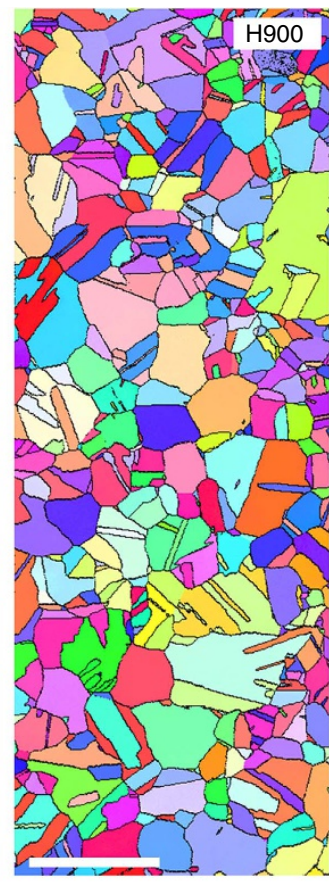

$D: 5.2 \pm 1.4 \mu \mathrm{m}$

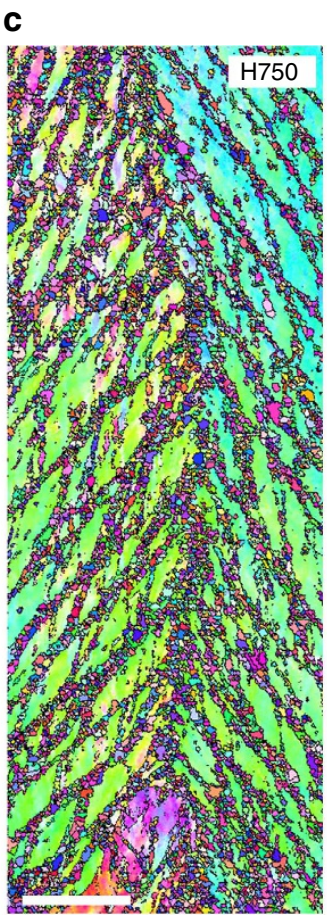

$D_{\text {Rex }}: 1.5 \pm 0.5 \mu \mathrm{m}$

$D_{\text {Non-rex }}: 32.0 \pm 9.5 \mu \mathrm{m}$ d

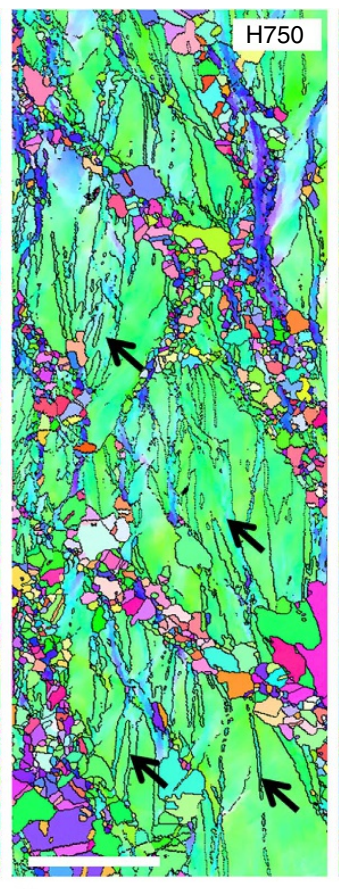

R Rolling twin e

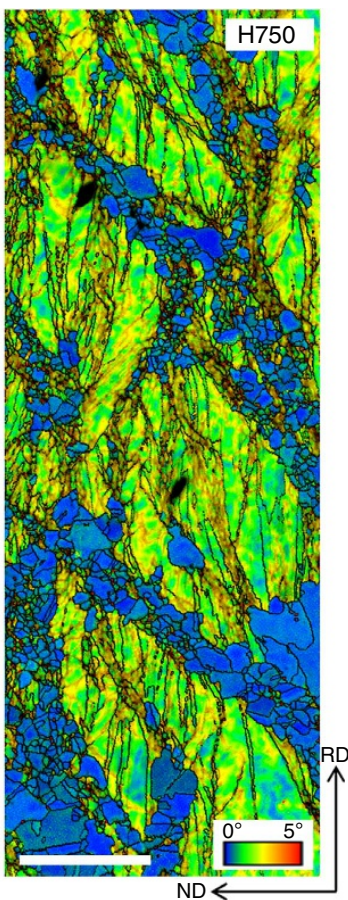

$\mathrm{ND} \longleftarrow$

Figure 2 | Microstructures of as-homogenized and annealed alloys. (a) IPF map from an EBSD scan of the as-homogenized alloy, showing very coarse fcc-single-phase grains (average grain size: $157 \mu \mathrm{m}$ ). (b) IPF map of the H900 alloy, showing recrystallized fcc-single-phase grains (average grain size: $5.2 \mu \mathrm{m}$ ). (c) IPF map of the $\mathrm{H} 750$ alloy, showing fine recrystallized fcc grains (average grain size: $\sim 1.5 \mu \mathrm{m}$ ) mixed with coarse non-recrystallized fcc grains (average grain size: $32 \mu \mathrm{m}$ ). (d,e) Higher-magnification IPF and IQ with KAM maps of the partially recrystallized microstructure in the H750 alloy. The fine recrystallized grains are mostly aligned along the $35-65^{\circ}$ direction, and a number of deformation twins with a $60^{\circ}$-twin orientation to the matrix are observed at the non-recrystallized grains. The scale bars in a-e are 100, 10,60, 10 and $10 \mu \mathrm{m}$, respectively.

This difference indicates that the dislocation density is relatively high near twins retained after cold rolling, which can lead to improvements in yield and tensile strength.

Tensile properties. Figure 3 shows the room- and cryogenictemperature engineering stress-strain curves of the H750 and $\mathrm{H} 900$ alloys. At room temperature, the H900 alloy shows a yield and tensile strengths of 498 and $752 \mathrm{MPa}$, respectively, along with an elongation of $52.5 \%$. The strengths are higher in the H750 alloy than in the H900 alloy, while the elongation is lower (28\%). At cryogenic temperatures, the strengths and elongation are improved over the room-temperature values. In the H900 alloy, the yield strength, tensile strength and elongation are $698 \mathrm{MPa}, 1,128 \mathrm{MPa}$ and $78.6 \%$, respectively, at cryogenic temperatures. Higher yield and tensile strengths (970 and $1,314 \mathrm{MPa}$ ) and lower elongation (46.3\%) are also shown in the H750 alloy at cryogenic temperature. Here, the yield strength of 


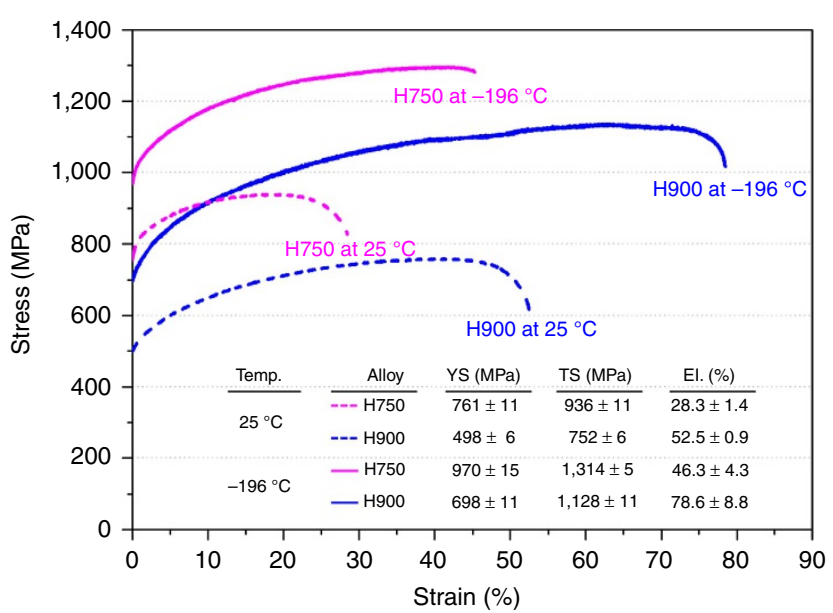

Figure 3 | Room- and cryogenic-temperature tensile properties.

Room- and cryogenic-temperature engineering stress-strain curves of the $\mathrm{H} 750$ and $\mathrm{H} 900$ alloys. At cryogenic temperatures, the strengths and elongation are improved over the room-temperature values. Higher yield and tensile strengths and lower elongation are shown in the H750 alloy. (The data points shown are the mean \pm s.d. from 3 repeated measurements).
$970 \mathrm{MPa}$ is a notable property. Yield strengths on the order of $1 \mathrm{GPa}$ have only rarely been achieved in existing annealed HEAs ${ }^{13-15,20}$.

Twin-related deformation mechanisms. To explain the strength improvement as well as the excellent cryogenic tensile properties shown in the fully recrystallized H900 and partially recrystallized H750 alloys, detailed tensile deformation behaviour is essentially needed. Figure $4 \mathrm{a}-\mathrm{h}$ shows EBSD IPF maps, IQ maps, transmission electron microscopy (TEM) bright- and dark-field (BF and DF) images, and selected-area diffraction (SAD) patterns of the cross-sectional area beneath the room- and cryogenictemperature tensile-fractured surface of the H900 alloy. In the room-temperature IPF and IQ maps (Fig. 4a,b), deformation twins are hardly found. In the TEM BF image, this area consists of high-density tangled dislocations without any twins (Fig. 4c). This observation is confirmed from the SAD pattern taken along the [011] zone axis of an fcc grain (Fig. 4d), which shows no twinning spots. At cryogenic temperatures, deformation twins are clearly observed, as indicated by the arrows in Fig. 4e. When twins are thinly formed, their definition is quite poor in the IPF map. According to the IQ map (Fig. 4f), several sharp twins are observed. These twins are also found in the TEM DF image (Fig. 4g). Many parallel twins with thicknesses of 10-30 nm were

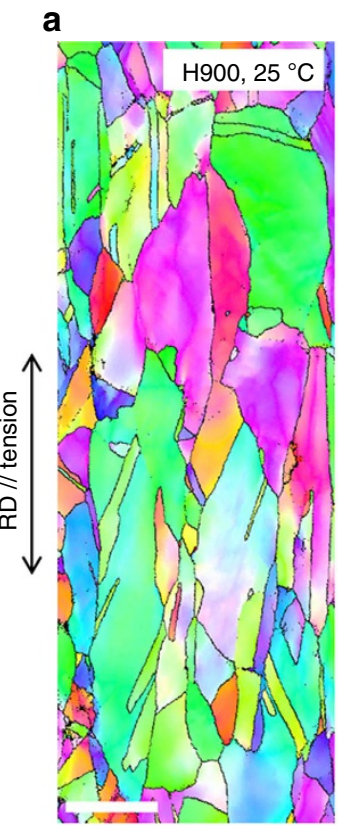

b

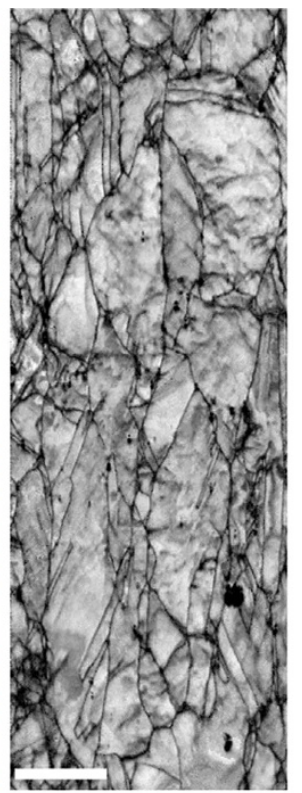

\section{C}

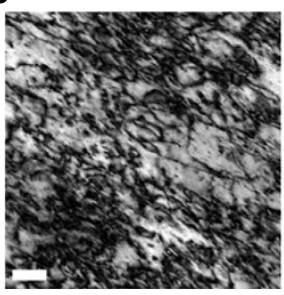

d

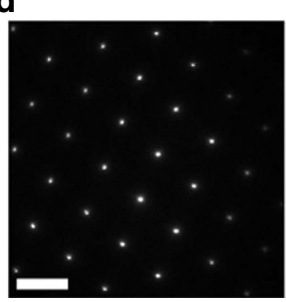

e

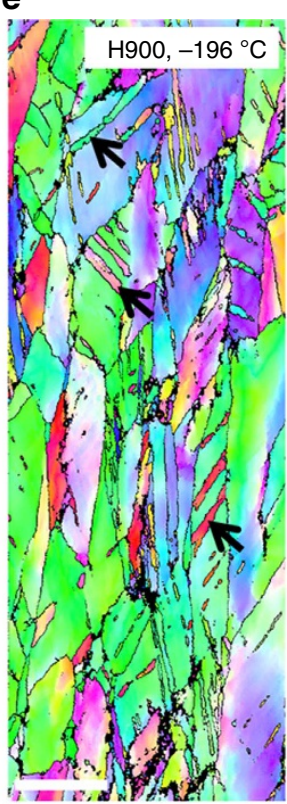

Nension twin

g

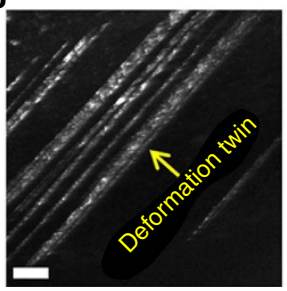

f

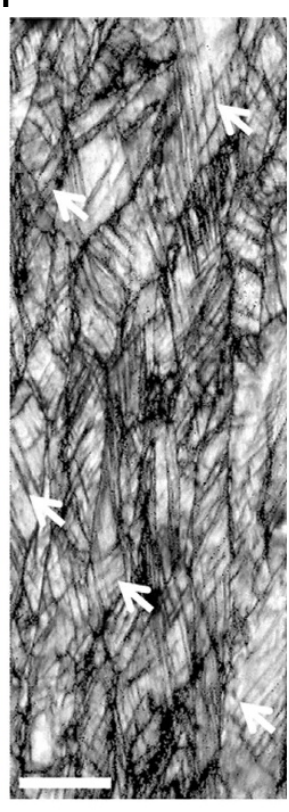

h

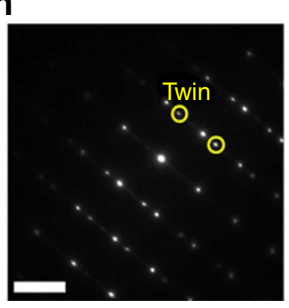

Figure 4 | Room- and cryogenic-temperature tensioned microstructures of $\mathbf{H 9 0 0}$ alloy. (a-d) IPF and IQ maps from an EBSD scan, TEM BF image and SAD pattern of the cross-sectional area beneath the room-temperature tensile-fractured surface showing very few deformation twins. The scale bars in a-d are $5 \mu \mathrm{m}, 5 \mu \mathrm{m}, 50 \mathrm{~nm}$ and $5 \mathrm{~nm}^{-1}$, respectively. (e-h) EBSD IPF map, IQ map, TEM DF image and SAD pattern of the cross-sectional area beneath the cryogenic-temperature tensile-fractured surface, showing many deformation twins. The scale bars in e-h are $5 \mu \mathrm{m}, 5 \mu \mathrm{m}, 50 \mathrm{~nm}$ and $5 \mathrm{~nm}-1$, respectively. 


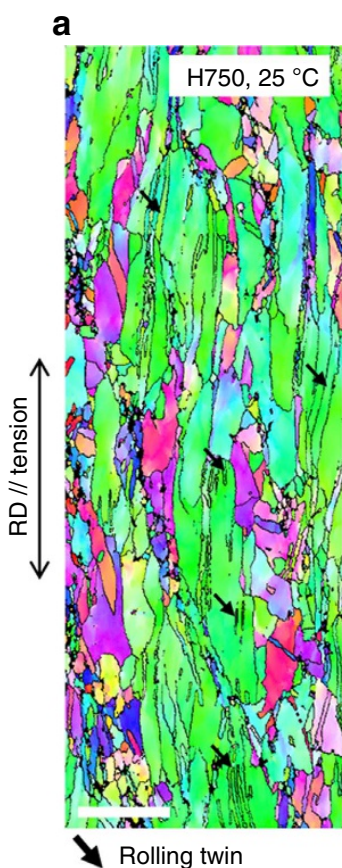

b

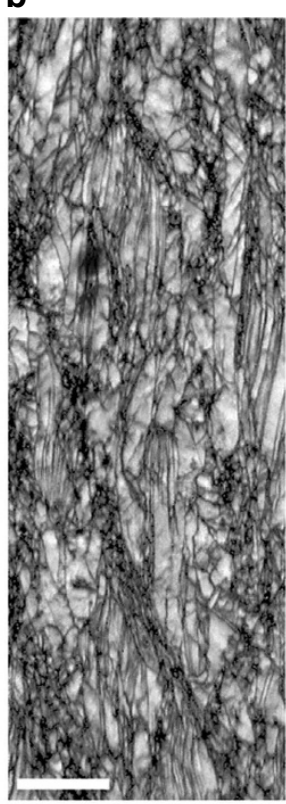

e

Recrystallized grain

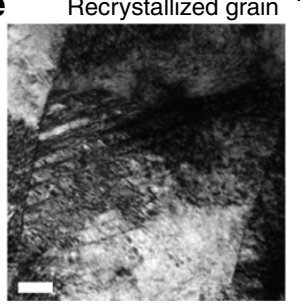

C

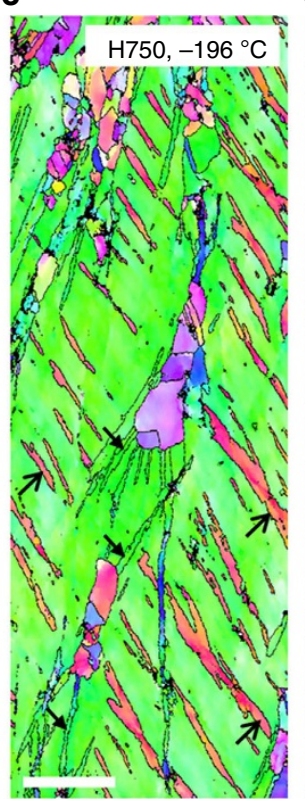

Tension twin

g Non-recrystallized grain d

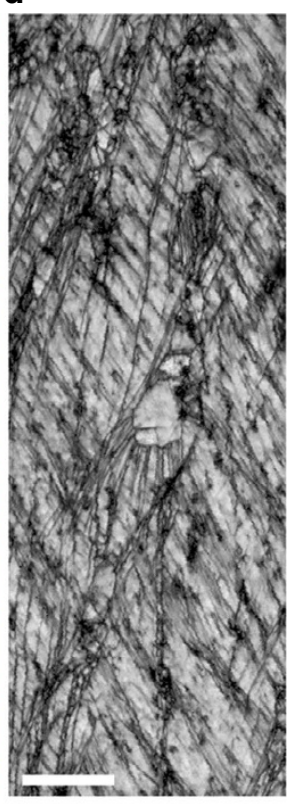

$\mathbf{h}$

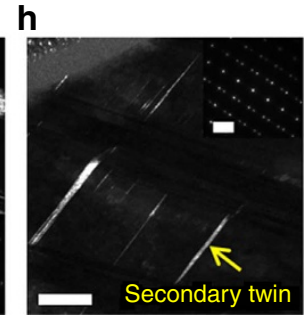

Figure 5 | Room- and cryogenic-temperature tensioned microstructures of $\mathbf{H 7 5 0}$ alloy. (a,b) IPF and IQ maps from an EBSD scan of the cross-sectional area beneath the room-temperature tensile-fractured surface, showing that most twins are retained after cold rolling, which indicates that there are no or few additional twins formed. The scale bars in $\mathbf{a}, \mathbf{b}$ are $5 \mu \mathrm{m}$. (c-h) IPF map, IQ map, TEM BF and DF images, and SAD patterns of the cross-sectional area beneath the cryogenic-temperature tensile-fractured surface, showing many primary deformation twins at the recrystallized grain and a further-increased number of primary and secondary deformation twins at the non-recrystallized grain. The scale bars in $\mathbf{c}-\mathbf{h}$ are $5 \mu \mathrm{m}, 5 \mu \mathrm{m}, 50 \mathrm{~nm}$, $50 \mathrm{~nm}, 500 \mathrm{~nm}$ and $500 \mathrm{~nm}$, respectively. The scale bars in the insets of $\mathbf{f}, \mathbf{h}$ are $5 \mathrm{~nm}^{-1}$.

observed, which was confirmed by the twinning spots in the SAD pattern (Fig. 4h); however, these twins did not develop into secondary twins.

Figure $5 \mathrm{a}-\mathrm{d}$ shows the EBSD IPF and IQ maps of the cross-sectional area beneath the room- and cryogenic-temperature tensile-fractured surface of the H750 alloy. As shown in Fig. 2d,e, the H750 alloy shows a partially recrystallized microstructure mixed with fine recrystallized grains and coarse non-recrystallized grains before the tension. A considerable number of twins formed during cold rolling are retained inside the non-recrystallized grains. After the tensile deformation at room temperature, many twins are observed (Fig. 5a,b), but most are twins retained after cold rolling, which indicates that there are no or few additional twins formed at room temperature. At cryogenic temperatures, a number of parallel twins having $60^{\circ}$-twin orientation are observed at the non-recrystallized grains, and the number and area fraction of twins are larger than those before the tension (Fig. $5 c$,d), which indicates that new twins having different orientations from the twins retained after cold rolling are formed, as marked by the arrows. Figure $5 \mathrm{e}-\mathrm{h}$ shows $\mathrm{BF}$ and DF images and SAD patterns of the recrystallized and non-recrystallized grains of the cryogenic-temperature tensioned H750 alloy. Fine twins of $10-30 \mathrm{~nm}$ in thickness are formed in one primary system at the recrystallized grain (Fig. 5e,f), similarly to the cryogenic-temperature tensioned H900 alloy (Fig. 4g,h). At the non-recrystallized grain, however, primary twin bundles of $\sim 500 \mathrm{~nm}$ in thickness (Fig. $5 \mathrm{~g}$ ) are formed together with fine secondary twins of $30-70 \mathrm{~nm}$ in thickness (Fig. 5h). These TEM observations confirm that additional twins are formed after the cryogenic-temperature tension at the non-recrystallized grains.

\section{Discussion}

The present $10 \mathrm{~V} 15 \mathrm{Cr} 5 \mathrm{Mn} 35 \mathrm{Fe} 10 \mathrm{Co} 25 \mathrm{Ni}$ alloy with a non-equiatomic composition is newly designed by thermodynamic calculations. An fcc single-phase microstructure is achieved after homogenization and annealing (Fig. 1c), which is in good agreement with the thermodynamic calculation results (Fig. 1b). When the grains are fully recrystallized (average grain size: $\sim 5.2 \mu \mathrm{m}$ ), the major deformation mechanism is a dislocation slip at room temperature, which changes to deformation twinning at cryogenic temperatures, similarly to the $\mathrm{CrMnFeCoNi}$ alloy. The cryogenic tensile properties (tensile strength: 1,128 MPa; elongation: $78.6 \%$ ) are similar to the previously published data of the CrMnFeCoNi alloy ${ }^{14}$. Notably, the yield strength is 
much higher $(698 \mathrm{MPa})$ than the reported yield strengths (200-600 MPa) of the CrMnFeCoNi alloy with similar grain sizes. This difference might be because the addition of vanadium plays a role in solid-solution hardening, which is the purpose of the present alloy design; however, other alloying elements are also varied. In the $\mathrm{H} 750$ alloy with a microstructure of mixed recrystallized and non-recrystallized grains, the effect of the non-recrystallized grains on yield strength improvement is quite obvious. Approximately $60 \mathrm{vol} \%$ of the coarse-grained non-recrystallized region as well as the fine-grained recrystallized region raise the room- and cryogenic-temperature yield strengths by $\sim 270 \mathrm{MPa}$ over those of the H900 alloy or by $\sim 370 \mathrm{MPa}$ over those of the CrMnFeCoNi alloy ${ }^{14}$.

The role of this non-recrystallized region in significantly improving the yield strength comes from the deformation twins formed during cold rolling. Notably, several thick twins are formed after cold rolling, as confirmed in the microstructure of the H750 alloy (Fig. 2d,e), whereas there are no deformation twins when the $\mathrm{H} 900$ alloy composed of recrystallized grains is tensioned at room temperature (Fig. $4 \mathrm{a}-\mathrm{d}$ ). This difference is attributed to the effect of grain size, which influences the critical stress for twinning. As indicated by Meyers et al. ${ }^{26}$, a highly unique characteristic of twinning is that the critical stress for twinning $\left(\sigma_{\mathrm{T}}\right)$ is more dependent on the grain size $(d)$ than the critical stress for slip $\left(\sigma_{\mathrm{S}}\right)$. For most cases, a Hall-Petch relationship is obeyed, where the slope for twinning $\left(k_{\mathrm{T}}\right)$ is higher than the slope for slip $\left(k_{\mathrm{S}}\right)$ in the following Hall-Petch equations:

$$
\begin{gathered}
\sigma_{\mathrm{T}}=\sigma_{\mathrm{T} 0}+k_{\mathrm{T}} d^{-1 / 2} \\
\sigma_{\mathrm{S}}=\sigma_{\mathrm{S} 0}+k_{\mathrm{S}} d^{-1 / 2}
\end{gathered}
$$

As the grain size increases, $\sigma_{\mathrm{T}}$ becomes smaller than $\sigma_{\mathrm{S}}$, which provides a good explanation for the profuse twinning at large grains.

The recent results from El-Danaf et al. $^{40}$ reconfirm the significant effect of grain size on the propensity for twinning. A $70 / 30$ brass with an average grain size of $250 \mu \mathrm{m}$ showed a much higher twinning density than that with average grain sizes of 9 or $30 \mu \mathrm{m}$. A $35 \mathrm{Ni} 35 \mathrm{Co} 20 \mathrm{Cr} 10 \mathrm{Mo}$ (at.\%) alloy with an average grain size of $40 \mu \mathrm{m}$ readily showed twinning, whereas the same alloy with an average grain size of $1 \mu \mathrm{m}$ did not show any evidence of twinning ${ }^{40}$. Meyers et al. ${ }^{41}$ performed shock-compression experiments on copper and obtained profuse twins when its average grain sizes were 117 or $315 \mu \mathrm{m}$, while no twins were found for an average grain size of $9 \mu \mathrm{m}$. These results indicate that grain coarsening promotes twinning rather than slip. Thus, twins are readily formed by cold rolling in the coarse microstructure without the grain refinement by hot rolling, similarly to the $\mathrm{H} 750$ alloy. However, the H900 alloy composed of fine recrystallized grains hardly obtains any twins.

The most important result for the $\mathrm{H} 750$ alloy is the presence of deformation twins inside the coarse non-recrystallized grains retained after cold rolling. Because these twins have a higher thermal stability than dislocations after the initial recovery occurring during annealing at $750^{\circ} \mathrm{C}$, these twins are retained at room temperature inside the coarse non-recrystallized grains, while the dislocation density is lowered by the formation of sub-structures ${ }^{42-44}$. Consequently, when considering the higher dislocation density near twins (Fig. 2e), these twins enhance the yield strength because they act as strong barriers against mobile dislocations. When the $\mathrm{H} 750$ alloy is tensioned at cryogenic temperatures, many new deformation twins are formed (tension twins), and twins are retained at the non-recrystallized grains at room temperature after cold rolling (rolling twins).
Because the system of newly formed cryogenic-temperature twins is different from that of room-temperature twins (Fig. 5a,c), the fraction of twins that can be formed during the room-temperature deformation is likely saturated; however, the deformation mode during cold rolling is different from that during the tensile test ${ }^{45}$. Thus, the populated formation of cryogenic-temperature twins, together with deformation twins retained at room temperature, readily leads to a high strainhardening effect and ultra-high yield and tensile strengths (970 and 1,314 MPa) at cryogenic temperatures (Fig. 3).

This study of deformation twins provides a good method for improving the cryogenic-temperature tensile properties in the present thermodynamically designed HEA. Considering the effects of grain size on the critical stress for twinning, twins are formed at room temperature by cold rolling right after homogenization without hot rolling, which can usually provide grain refinement. These twins are retained by partial recrystallization and utilized as a powerful mechanism for improving the cryogenic-temperature yield and tensile strengths. The tensile properties of the present annealed HEAs exceed, to our knowledge, properties reported so far to date in past studies on HEAs. In particular, the present ultra-high yield strength (near-1 GPa grade) is achieved mainly by the existence of non-recrystallized grains, and the yield strength also benefits from the formation of fine recrystallized grains. The persistent elongation of up to $46 \%$ as well as the ultra-high yield and tensile strengths in the H750 alloy are attributed to the additional twinning in both the recrystallized and non-recrystallization regions. The merits of a good combination of strength and ductility and a simple manufacturing process of the present $10 \mathrm{~V} 15 \mathrm{Cr} 5 \mathrm{Mn} 35 \mathrm{Fe} 10 \mathrm{Co} 25 \mathrm{Ni}$ alloy are promising as new applications in ultra-high-strength HEAs, particularly those at cryogenic temperatures. Our results also reveal that room-temperature deformation twinning coupled with non-recrystallization can offer a strengthening mechanism for ultra-high-strength HEAs.

\section{Methods}

Fabrication of 10V15Cr5Mn35Fe10Co25Ni HEA. An alloy designed by thermodynamic calculations was fabricated by compact vacuum induction melting equipment (model: MC100V, Indutherm, Walzbachtal-Wossingen, Germany) under an argon atmosphere. The master alloys were prepared from commercially pure elements (the purity of each raw material was at least 99.9\%). The raw elements were alloyed in a $\mathrm{ZrO}_{2}$-coated $\mathrm{Al}_{2} \mathrm{O}_{3}$ ceramic crucible in a vacuum induction melting furnace. The $\mathrm{Al}_{2} \mathrm{O}_{3}$ crucible was heated to $600^{\circ} \mathrm{C}$ for $1 \mathrm{~h}$ to remove the water vapour before placing it into a furnace. The pouring temperature was set to $1,500{ }^{\circ} \mathrm{C}$. Approximately $150 \mathrm{~g}$ of the master alloy was melted, superheated and poured into a rectangular graphite module with a length of $100 \mathrm{~mm}$, width of $35 \mathrm{~mm}$ and thickness of $8 \mathrm{~mm}$. Before melting, the furnace chamber was evacuated to $6 \times 10^{-2} \mathrm{~Pa}$ and backfilled with high-purity argon gas to reach $0.06 \mathrm{MPa}$. Each alloy ingot was melted three or four times to ensure compositional homogeneity. The ingots were homogenized at $1,100^{\circ} \mathrm{C}$ for $6 \mathrm{~h}$, pickled in $20 \% \mathrm{HCl}$ and milled to a thicknesses of $7 \mathrm{~mm}$. The pickled ingots were rolled at room temperature (reduction ratio: $75 \%$ ) to produce 1.5 -mm-thick sheets. The alloy sheets were annealed at 750 and $900^{\circ} \mathrm{C}$ for $10 \mathrm{~min}$ to obtain partially and fully recrystallized microstructures, respectively, and were quenched with water.

Microstructure characterization. The phases present in the alloy sheets were identified by $\mathrm{X}$-ray diffraction $\left(\mathrm{Cu} \mathrm{K}_{\alpha}\right.$ radiation, scan rate: 2 deg per min, scan step size: $0.02 \mathrm{deg}$ ). EBSD analysis (step size: $0.07 \mu \mathrm{m}$ ) was also conducted using a field emission scanning electron microscope (FE-SEM, Quanta 3D FEG, FEI Company, USA). EBSD specimens were mechanically polished and electro-polished at room temperature in a solution of $\mathrm{CH}_{3} \mathrm{COOH}(92 \%)$ and $\mathrm{HClO}_{4}(8 \%)$ at an operating voltage of $32 \mathrm{~V}$. The data were interpreted by orientation imaging microscopy analysis software provided by TexSEM Laboratories, Inc. The KAM was calculated up to the fifth neighbour shell with a maximum misorientation angle of $5^{\circ}$ (ref. 46). The KAM maps served as a measure of the deformation-induced local orientation gradients inside the grains. Deformed microstructures were identified by TEM (model: 2,100, JEOL, Japan) at an acceleration voltage of $200 \mathrm{kV}$. 
Focused-ion beam (FIB, model: Quanta 3D FEG, FEI Company, USA) was used to prepare TEM thin foils.

Mechanical property tests. Plate-type sub-sized tensile specimens with a gauge length of $6.4 \mathrm{~mm}$, gauge width of $2.5 \mathrm{~mm}$ and gauge thickness of $1.5 \mathrm{~mm}$ were prepared in the longitudinal direction. The specimens were tested at room and cryogenic temperatures $\left(-196^{\circ} \mathrm{C}\right)$ at a crosshead speed of $6.4 \times 10^{-3} \mathrm{~mm} \mathrm{~s}^{-1}$ by using a universal testing machine (model: 8,801 , Instron, Canton, MA, USA) with a $100-\mathrm{kN}$ capacity. A low-temperature chamber (size: $50 \times 40 \times 38 \mathrm{~cm}$ ) was attached into the universal testing machine in the case of the cryogenic-temperature tensile test by placing the specimen in liquid $\mathrm{N}_{2}$ and equilibrating it. The representative data were obtained by averaging three values at each datum point and are reported with the s.d.

Data availability. The data that support the findings of this study are available from the corresponding author upon reasonable request.

\section{References}

1. Senkov, O. N., Wilks, G. B., Scott, J. M. \& Miracle, D. B. Mechanical properties of $\mathrm{Nb}_{25} \mathrm{Mo}_{25} \mathrm{Ta}_{25} \mathrm{~W}_{25}$ and $\mathrm{V}_{20} \mathrm{Nb}_{20} \mathrm{Mo}_{20} \mathrm{Ta}_{20} \mathrm{~W}_{20}$ refractory high entropy alloys. Intermetallics 19, 698-706 (2011).

2. Lucas, M. S. et al. Absence of long-range chemical ordering in equimolar FeCoCrNi. Appl. Phys. Lett. 100, 251907 (2012).

3. Wu, Z., Bei, H., Otto, F., Pharr, G. M. \& George, E. P. Recovery, recrystallization, grain growth and phase stability of a family of FCC-structured multi-component equiatomic solid solution alloys. Intermetallics 46, 131-140 (2014).

4. Kozak, R., Sologubenko, A. \& Steurer, W. Single-phase high-entropy alloys-an overview. Z. Kristallogr. 230, 55-68 (2015).

5. Otto, F. et al. Decomposition of the single-phase high-entropy alloy $\mathrm{CrMnFeCoNi}$ after prolonged anneals at intermediate temperatures. Acta Mater. 112, 40-52 (2016).

6. Zhang, Y. et al. Microstructures and properties of high-entropy alloys. Prog. Mater. Sci. 61, 1-93 (2014)

7. Tsai, M. H. \& Yeh, J. W. High-entropy alloys: a critical review. Mater. Res. Lett. 2, 107-123 (2014)

8. Senkov, O. N., Senkova, S. V., Woodward, C. \& Miracle, D. B. Low-density, refractory multi-principal element alloys of the $\mathrm{Cr}-\mathrm{Nb}-\mathrm{Ti}-\mathrm{V}-\mathrm{Zr}$ system: microstructure and phase analysis. Acta Mater. 61, 1545-1557 (2013).

9. Yang, X., Zhang, Y. \& Liaw, P. K. Microstructure and compressive properties of NbTiVTaAlx high entropy alloys. Procedia Eng 36, 292-298 (2012).

10. Yeh, J. W. et al. Nanostructured high-entropy alloys with multiple principal elements: novel alloy design concepts and outcomes. Adv. Eng. Mater. 6, 299-303 (2004).

11. Youssef, K. M., Zaddach, A. J., Niu, C., Irving, D. L. \& Koch, C. C. A novel low-density, high-hardness, high-entropy alloy with close-packed single-phase nanocrystalline structures. Mater. Res. Lett. 3, 95-99 (2015).

12. Cantor, B., Chang, I. T. H., Knight, P. \& Vincent, A. J. B. Microstructural development in equiatomic multicomponent alloys. Mater. Sci. Eng. A 375, 213-218 (2004)

13. Gali, A. \& George, E. P. Tensile properties of high-and medium-entropy alloys. Intermetallics 39, 74-78 (2013).

14. Otto, F. et al. The influences of temperature and microstructure on the tensile properties of a CoCrFeMnNi high-entropy alloy. Acta Mater. 61, 5743-5755 (2013).

15. Gludovatz, B. et al. A fracture-resistant high-entropy alloy for cryogenic applications. Science 345, 1153-1158 (2014).

16. Dongyue, L. et al. High-entropy $\mathrm{Al}_{0.3} \mathrm{CoCrFeNi}$ alloy fibers with high tensile strength and ductility at ambient and cryogenic temperatures. Acta Mater. 123, 285-294 (2017).

17. Dongyue, L. \& Yong, Z. The ultrahigh charpy impact toughness of forged AlxCoCrFeNi high entropy alloys at room and cryogenic temperatures. Intermetallics 70, 24-28 (2016).

18. Chen, Y. Y., Duval, T., Hung, U. D., Yeh, J. W. \& Shih, H. C. Microstructure and electrochemical properties of high entropy alloys-a comparison with type-304 stainless steel. Corros. Sci. 47, 2257-2279 (2005).

19. Hsu, Y. J., Chiang, W. C. \& Wu, J. K. Corrosion behavior of $\mathrm{FeCoNiCrCu}_{\mathrm{x}}$ high-entropy alloys in 3.5\% sodium chloride solution. Mater. Chem. Phys. 92, 112-117 (2005)

20. Laplanche, G., Kostka, A., Horst, O. M., Eggeler, G. \& George, E. P. Microstructure evolution and critical stress for twinning in the $\mathrm{CrMnFeCoNi}$ high-entropy alloy. Acta Mater. 118, 152-163 (2016).

21. Zhu, Y. T. et al. Nucleation and growth of deformation twins in nanocrystalline aluminum. Appl. Phys. Lett. 85, 5049-5051 (2004).

22. Wang, Z. et al. The effect of interstitial carbon on the mechanical properties and dislocation substructure evolution in $\mathrm{Fe}_{40.4} \mathrm{Ni}_{11.3} \mathrm{Mn}_{34.8} \mathrm{Al}_{7.5} \mathrm{Cr}_{6}$ high entropy alloys. Acta Mater. 120, 228-239 (2016).
23. Ueji, R. et al. Tensile properties and twinning behavior of high manganese austenitic steel with fine-grained structure. Scr. Mater. 59, 963-966 (2008).

24. Grässel, O., Krüger, L., Frommeyer, G. \& Meyer, L. W. High strength Fe-Mn-(Al, Si) TRIP/TWIP steels development-properties-application. Int. J. Plast. 16, 1391-1409 (2000).

25. Schuh, B. et al. Mechanical properties, microstructure and thermal stability of a nanocrystalline $\mathrm{CoCrFeMnNi}$ high-entropy alloy after severe plastic deformation. Acta Mater. 96, 258-268 (2015).

26. Meyers, M. A., Vöhringer, O. \& Lubarda, V. A. The onset of twinning in metals: a constitutive description. Acta Mater. 49, 4025-4039 (2001).

27. Stepanov, N. et al. Effect of cryo-deformation on structure and properties of CoCrFeNiMn high-entropy alloy. Intermetallics 59, 8-17 (2015).

28. Williams, J. C. \& Starke, E. A. Progress in structural materials for aerospace systems. Acta Mater. 51, 5775-5799 (2003).

29. Reed, R. C., Zhu, Z., Sato, A. \& Crudden, D. J. Isolation and testing of new single crystal superalloys using alloys-by-design method. Mater. Sci. Eng. A 667, 261-278 (2016).

30. Li, C., Li, J. C., Zhao, M. \& Jiang, Q. Effect of alloying elements on microstructure and properties of multiprincipal elements high-entropy alloys. J. Alloy Compd. 475, 752-757 (2009).

31. Tsai, D. C., Shieu, F. S., Chang, S. Y., Yao, H. C. \& Deng, M. J. Structures and characterizations of TiVCr and TiVCrZrY films deposited by magnetron sputtering under different bias powers. J. Electrochem. Soc. 157, K52-K58 (2010).

32. Varalakshmi, S., Kamaraj, M. \& Murty, B. S. Formation and stability of equiatomic and nonequiatomic nanocrystalline CuNiCoZnAlTi high-entropy alloys by mechanical alloying. Metall. Mater. Trans. A 41A, 2703-2709 (2010).

33. Zhang, H., Pan, Y. \& He, Y. Z. Synthesis and characterization of FeCoNiCrCu high-entropy alloy coating by laser cladding. Mater. Des. 32, 1910-1915 (2011).

34. Zhang, K. B. et al. Microstructure and mechanical properties of CoCrFeNiTiAl ${ }_{\mathrm{x}}$ high-entropy alloys. Mater. Sci. Eng. A 508, 214-219 (2009).

35. Zhang, Y., Zhou, Y. J., Lin, J. P., Chen, G. L. \& Liaw, P. K. Solid-solution phase formation rules for multi-component alloys. Adv. Eng. Mater. 10, 534-538 (2008).

36. de Boer, F. R., Boom, R., Mattens, W. C. M., Miedema, A. R. \& Niessen, A. K. Cohesion in metals: Transition Metal Alloys (North-Holland, 1988).

37. Sundman, B., Jansson, B. \& Andersson, J. O. The thermo-calc databank system. Calphad 9, 153-190 (1985).

38. Lee, B. J. \& Sundman, B. TCFE2000: the Thermo-Calc Steels Database (KTH, 1999).

39. Chin, K. G., Lee, H. J., Kwak, J. H., Kang, J. Y. \& Lee, B. J. Thermodynamic calculation on the stability of $(\mathrm{Fe}, \mathrm{Mn})_{3} \mathrm{AlC}$ carbide in high aluminum steels. J. Alloy Compd. 505, 217-223 (2010).

40. El-Danaf, E., Kalidindi, S. R. \& Doherty, R. D. Influence of grain size and stacking-fault energy on deformation twinning in fcc metals. Metall. Mater. Trans. A 30A, 1223-1233 (1999).

41. Meyers, M. A., Andrade, U. R. \& Chokshi, A. H. The effect of grain size on the high-strain, high-strain-rate behavior of copper. Metall. Mater. Trans. A 26A 2881-2893 (1995).

42. Bouaziz, O., Scott, C. P. \& Petitgand, G. Nanostructured steel with high workhardening by the exploitation of the thermal stability of mechanically induced twins. Scr. Mater. 60, 714-716 (2009).

43. Dini, G., Najafizadeh, A., Ueji, R. \& Monir-Vaghefi, S. M. Improved tensile properties of partially recrystallized submicron grained TWIP steel. Mater. Lett. 64, 15-18 (2010).

44. Rangaraju, N., Raghuram, T., Krishna, B. V., Rao, K. P. \& Venugopal, P. Effect of cryo-rolling and annealing on microstructure and properties of commercially pure aluminium. Mater. Sci. Eng. A 398, 246-251 (2005).

45. Zhou, P., Liang, Z. Y., Liu, R. D. \& Huang, M. X. Evolution of dislocations and twins in a strong and ductile nanotwinned steel. Acta Mater. 111, 96-107 (2016).

46. Britton, T. B., Birosca, S., Preuss, M. \& Wilkinson, A. J. Electron backscatter diffraction study of dislocation content of a macrozone in hot-rolled Ti-6Al-4 V alloy. Scr. Mater. 62, 639-642 (2010).

\section{Acknowledgements}

We thank Dr A. Zargaran of POSTECH for the TEM analysis. This work was supported by the Future Material Discovery Project of the National Research Foundation of Korea (NRF) funded by the Ministry of Science, ICT and the Future Planning (MSIP) of Korea (NRF-2016M3D1A1023383) and by the Brain Korea 21 PLUS Project for Center for Creative Industrial Materials. 


\section{Author contributions}

Y.H.J., S.S.S., H.S.K., N.J.K. and S.L. designed the experiments. Y.H.J. and S.J. performed all the experiments. W.M.C. and B.J.L. conducted the thermodynamic calculations. Y.H.J., S.S.S., N.J.K. and S.L. analysed the data. S.S.S., B.J.L., N.J.K. and S.L. wrote the manuscript with contributions from the other authors. All authors commented on the final manuscript and conclusions of this work.

\section{Additional information}

Competing interests: The authors declare no competing financial interests.

Reprints and permission information is available online at http://npg.nature.com/ reprintsandpermissions/

How to cite this article: Jo, Y. H. et al. Cryogenic strength improvement by utilizing room-temperature deformation twinning in a partially recrystallized VCrMnFeCoNi high-entropy alloy. Nat. Commun. 8, 15719 doi: 10.1038/ncomms15719 (2017).
Publisher's note: Springer Nature remains neutral with regard to jurisdictional claims in published maps and institutional affiliations.

(c) Open Access This article is licensed under a Creative Commons Attribution 4.0 International License, which permits use, sharing, adaptation, distribution and reproduction in any medium or format, as long as you give appropriate credit to the original author(s) and the source, provide a link to the Creative Commons license, and indicate if changes were made. The images or other third party material in this article are included in the article's Creative Commons license, unless indicated otherwise in a credit line to the material. If material is not included in the article's Creative Commons license and your intended use is not permitted by statutory regulation or exceeds the permitted use, you will need to obtain permission directly from the copyright holder. To view a copy of this license, visit http://creativecommons.org/ licenses/by/4.0/

(C) The Author(s) 2017 